\title{
Dirty Hands, Speculative Minds, and Smart Machines
}

\author{
Diane P. Michelfelder
}

Received: 20 October 2010 / Accepted: 10 December 2010 /Published online: 30 December 2010

(C) The Author(s) 2010. This article is published with open access at Springerlink.com

\begin{abstract}
In 2003, Peter Singer and others sounded a warning in the pages of the journal Nanotechnology that research into the ethical, social, and legal implications (ELSI) of nanotechnology was increasingly lagging behind research into nanotechnology itself. More recently, Alfred Nordmann and Arie Rip have argued that while the pace of ELSI inquiry has now picked up, the inquiry itself is focused far too much on hypothetical and futuristic scenarios. But might there be advantages for ethicists and philosophers of technology interested in the ELSI of emerging technologies to continue to think in a speculative vein? Drawing upon some lessons learned from the development of environmental ethics, and looking primarily at information and computing technologies, I suggest three reasons as to how speculative thinking can add value to ELSI reflection. I argue that it can allow for critical values to emerge that might otherwise go unheeded, open up avenues to reframe issues that might otherwise go unnoticed, and, perhaps most importantly, permit questions to be raised that might otherwise go unvoiced.
\end{abstract}

Keywords Ethics $\cdot$ Emerging technologies $\cdot$ Information and computing technologies $\cdot$ Speculative ethical thinking

Philosophical challenges related to thinking about the ethical, social, and legal (ELSI) consequences of information and computing technology (ICT) tend to fall into one of two categories. Questions such as whether the developers of Facebook should do more to protect the privacy interests of its users, or whether the US government violates its own laws regarding search warrants when secretly placing GPS devices on the cars of those about whom it is interested in secretly gathering information, are representative of one category of philosophical challenges. The question of whether social media sites in general lead individuals to become more casual about revealing personal information, in turn promoting a society that is more

D. P. Michelfelder $(\bowtie)$

Department of Philosophy, Macalester College, 1600 Grand Avenue, Saint Paul, MN 55105, USA

e-mail: michelfelder@macalester.edu 
accepting of individual, corporate, and government surveillance, is representative of another. One category is micro, and the other macro. Questions about the particular ethical and social impacts of specific technologies belong to one category. Questions in the second category cast a wider net. In this paper, I will not be turning my attention to any single development within ICT for the purpose of gaining a greater perspective on its possible ELSI consequences, and that is by deliberate intent. Rather, I am interested in taking a step back from such a scenario to explore a more general question within the provenance of the second category. What role ought philosophers, especially ethicists and philosophers of technology, to play in thinking about ICT-ELSI, and in working alongside engineers as well as public policy experts in the process of ICT design and policy formation?

\section{Background}

One answer to this question came in 2003, 13 years after the launch of the journal Nanotechnology, when Anisa Mnyusiwalla, Abdallah Daar, and Peter Singer sounded a warning in its pages under the title "“Mind the gap': science and ethics in nanotechnology" (Mnyusiwalla et al. 2003). Their warning called attention to what the authors perceived as the increasing divide between the explosive growth of innovation and acceleration of research within nanotechnology (NT), and the relative lack of research into the ELSI of NT, despite the availability of funding to support work in the latter field. In calling attention to this gap, Mnyusiwalla, Daar, and Singer were not simply interested in underscoring the simple fact that ethical reflection was lagging behind the pace of research and development in NT. More importantly, they wanted to stress the threat that the lack of ELSI-related research in NT posed to the advancement of science, given the potential that this research could have for positively influencing the public perception of NT's benefits and promises. As they put it bluntly: "Either the ethics of NT will catch up, or the science will slow down" (p. R12). Contained in this expression of concern is an implicit, simple response to the question of what ethicists and philosophers of technology need to do in responding to NT research: "Work harder."

Some 7 years later, we have come to learn that the science has not slowed down but rather intensified its pace. One clear indicator of this intensified pace can be seen in the fact that Nanotechnology, published monthly at the time "Mind the gap" appeared, now has a new issue every week. ${ }^{1}$ Does this quickened pace mean that NT-ELSI research has caught up with NT research itself? Not according to Alfred Nordmann and Arie Rip (2009). ${ }^{2}$ Nordmann and Rip argue that while there has been

\footnotetext{
${ }^{1}$ A host of other signs can be found to attest to the momentum of nanotechnology research. For instance, the number of US companies, universities, or other organizations contributing to the development of NT as reported in "Putting Nanotechnology on the Map" (Project for Emerging Technologies) jumped by 50\% from 2007 to 2009. The same source also indicates that the number of publicly reported nano-enabled consumer products now totals more than 1,000 .

2 Arie Rip discussed this paper, "Mind the gap revisited," while participating in a panel addressing the role for philosophers in the development of public policies for converging technologies, convened at the meeting of the Society for Philosophy and Technology in July 2009 at the University of Twente. Rip's reflections provided the impetus for the questions raised in this paper.
} 
a striking leap forward in the number of published papers and projects related to nanoethics, much of this work has been quite speculative in nature, focused not only on the hypothetical side of NT but precisely also on those possible developments, such as NT-enabled human enhancement or the use of nanomaterials in ambient intelligence, which are most likely to trigger fear and consequently rejection among the public at large.

Because much ELSI-related work has been so speculative in nature and so attuned to hypothetical developments in NT, Nordmann and Rip believe that another gap has sprung up, a gap between applications of NT that have actually seen the light of day and reflections on the important ethical questions to which these applications give rise. To close this gap, they recommend that ethicists should pay less attention to the future and futuristic scenarios and more to the here and now, less attention to NT in the singular (along with its rhetoric of transforming society), and more attention to nanotechnologies in the plural. In other words, ethicists should abandon "desk ethics" and get their hands dirty instead by turning their attention to analyzing the ELSI complexities associated with NTs already fairly advanced in their development. ${ }^{3}$

I have spent the time I have spelling out the arguments of these two papers because they serve to situate the line of thinking I want to develop here. A much more thorough consideration of Nordmann's and Rip's position can be found in an article published in Nanoethics by Armin Grunwald (2010), in which he challenges some of the basic assumptions of their paper. ${ }^{4}$ In challenging these assumptions, however, Grunwald does not mount a direct defense of speculative ethics. In a vein of thinking that can be applied to emerging technologies in general, he instead makes a case for separating nanoethics into two categories: applied nanoethics, which would include reflection on safety and equity issues in NT, with more speculative ethical reflection on matters such as nanobiotechnology falling under the category of "explorative philosophy of nanotechnology." The latter would "provide orientation but not any direct guidance for action" (p. 96); "no direct policy actions will depend on their results" (p. 99).

While this approach creates a thoughtful alternative to that suggested by Nordmann and Rip, I believe it is important for ethicists to continue to think about emerging technologies in a speculative vein, without limiting their role in this endeavor to the preparatory one recommended by Grunwald. One reason is that arguably, the more speculative ethicists do their work apart from policysetting contexts, the less their work is likely to have influence within them. A second, and related, concern about Grunwald's approach is that it appears to set exploratory philosophy of nanotechnology (or any other emerging technology) on a parallel track with technological development itself. Such an approach would run the risk, noted by Grunwald and others, of being unable to influence the course of that development, as results would appear too late on the scene to have influence

\footnotetext{
${ }^{3} \mathrm{I}$ am using the expression "dirty hands" in its colloquial sense of getting involved in the concrete ideas details of policy development.

${ }^{4}$ Specifically, Grunwald calls into question Nordmann's and Rip's contentions that current work in nanoethics is overwhelmingly speculative, that speculative nanoethics threatens public acceptance of NT, and that speculative ethics carries with it high opportunity costs.
} 
(p. 94). If both these points are plausible, then a consequence of making a differentiation between a fairly narrowly construed field of applied nanoethics and a more wide-open explorative philosophy of nanotechnology would be that concern for the big ethical picture would not play a direct role in the development either of policies for NT or of NT itself. And that, as I hope to show in what follows primarily with regard to speculative ethics of emerging ICTs, would be a critical opportunity lost.

In defending then the claim in the remainder of this paper that there is a need for a speculative ethics of emerging technologies, my intent is not to pit targeted, objectoriented ELSI reflection against the breadth of speculative thinking. I simply wish to suggest that there are good reasons, three in particular, to give speculative ELSI reflection, specifically ELSI reflection focused on emerging ICTs, its due. Firstly, speculative thinking adds value to ICT-ELSI reflection because it can allow for important values to emerge that might otherwise go unheeded. Another benefit is that it can open up avenues that might otherwise go unnoticed for reframing and recasting issues. It can also, and perhaps most importantly, permit questions to be raised that might otherwise go unvoiced.

In defending the value of speculative thinking in the context of ICT-ELSI, I do not want to claim that it is important to think about each and every possible development related to transhumanism, robots as moral agents, or other futuristic scenarios. That would be neither feasible nor sensible. Priorities need to be worked out. But given the number of such scenarios, how can we decide which ones are worth our attention and which ones can be safely ignored? Toward the end of this paper, I will spend some time briefly sketching an answer to this difficult and important question.

\section{Making Hidden Values Visible}

In "Mind the gap," Mnyusiwalla, Daar, and Singer drew upon some lessons learned from thinking about the social impacts of fields more advanced than nanotechnology in their development, namely genomics and biotechnology, for pointers as to how research productivity focused on NT-ELSI might be increased. In defending the role of speculative thinking in consideration of ICT-ELSI issues, I also want to start with some lessons suggested by the development of another field more advanced in its development, that of environmental ethics. Why environmental ethics? The future of ICT is already and will continue to intersect and be interlocked with the future of NT, biotechnology, and cognitive science. It is not only advances in these separate emerging technologies that demand to be taken as objects of ethical consideration but also the overall technological environment resulting from this intersection within which our lived experience unfolds. The fact that the intersection of ICT with NT can lead to the hyperminiaturization of smart machines that, much like the atmosphere, blend into the environment below the threshold of perception, and so create, as Nordmann dubbed it, "naturalized technology," is an example of what I have in mind (Nordmann 2007). From this perspective, seeing what could be learned from the development of the ethics dealing with our responsibilities to the natural world seems a reasonable step to take. 
In a provocative and deftly argued collection of essays, The Economy of the Earth, Mark Sagoff describes how the American environmentalist movement of the mid-1970s emerged from a series of direly dystopian predictions prompting public fear that in a mere matter of decades, the world would not only bear witness to mass starvation due to food shortages caused by overpopulation but also run out of gold, petroleum, zinc, and other nonrenewable resources (Sagoff 2008). The timelines for many of these predictions have now expired; their warnings have been exposed as exaggerated and far-fetched. But in addition to helping spawn the environmentalism movement, these claims also gave rise to a substantive and valuable body of work in a new field of philosophical inquiry: environmental ethics. That they turned out to be far-fetched does not undermine the importance of the work done in this period in environmental ethics. It saw the flourishing of philosophical arguments, for example, that identified species and ecosystems as new objects of moral responsibility. It launched thoughtful and heated debate on the question of whether the values that could serve as a ground for our responsibilities were intrinsic or instrumental. As a "new generation" of issues such as climate change and sustainability arises within environmental ethics, Sagoff pleads for philosophers, when debating these issues, not to abandon the language of intrinsic value. In particular, he pleads for philosophers to continue to base their considerations of these newer issues on esthetic, spiritual, and ethically related values, including the value of place, and leave it to economists to offer reasons to protect the environment on a more pragmatic basis, such as for the resources it can provide to humans. ${ }^{5}$

While the optimism and bold hopes for social transformation reflected in predictions made in the first decade of this century regarding ICTs stand in sharp contrast with the dystopian predictions of the mid-1970s about the future of our planet, one of the ideas at least some of the former shares with the latter is that sweeping, dramatic change is but decades away. In their well-known report on converging technologies, Mihail Roco and William Bambridge noted that "Moving forward simultaneously along many of these [NBIC-related] paths could achieve an age of innovation and prosperity that would be a turning point in the evolution of human society," adding that "If we make the correct decisions and investments today, many of these visions could be addressed within 20 years' time." (Roco and Bambridge 2002). Among the ICT innovations predicted as potentially realizable within this time frame are brain and machine interfaces in the workplace, wearable computers and sensors that would monitor and transmit a wide spectrum of information on matters related to health and commerce, and robots designed to engage humans in more "natural" interactions (p. 5). A similar timeframe for successful innovation can be found in Microsoft's report: "Being Human: HumanComputer Interaction in the Year 2020," in which it is predicted that by that year, the landscape in which we live will be transformed into a "computational ecosystem" because ubiquitous computing will have become a reality (Harper et al. 2008).

At this point in time, it is fairly safe to say that when the year 2020 arrives, many of these bold aspirations will not yet be realized. The fact that it is fairly safe to say that this is a sign that the substance of these aspirations, much like the dire mid1970s warnings that the earth's carrying capacity was reaching its limits, is vastly

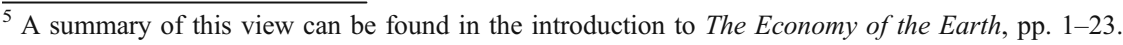


overstated, and not simply with regard to the timeframe in which these aspirations are projected to be accomplished.

That does not mean, however, that it is waste of time to give speculative consideration to what the ethical impacts associated with the world as a "computational ecosystem" might be, for instance, or to the ethical issues associated with neuromarketing, with developing robots as moral agents, or with "uplifting" nonhuman animals to emulate human cognitive abilities. Such consideration is mindful that even if the complexity, integrity, and interdependent relationships marking the development of innovations in bioinformatics and other ICT-related fields turn out to fall short of being a "computational ecosystem," it is the interrelationships among these innovations and the world that opens up as a result that pose moral challenges, just as much (if not more so) as do individual innovations themselves. In this context, ethical reflection attuned to what lies ahead is reflection attuned to the whole, and gaining perspective on the whole allows for particular values to emerge that might be obscured when attention is focused on the ELSI of individual ICT artifacts such as RFID chips or "smart" clothing or robotic pets for the elderly that function simultaneously to relieve stress and to monitor signs of health. Such wide-aperture ethical reflection forces the focus of thinking to be oriented toward deep, arguably foundational human values in ways that, routinely and as a matter of course, reflection on the impacts of specific applications does not.

While happiness and friendship are perhaps the most obvious candidates for the kinds of values that such wide-aperture reflection could bring to the fore, they are not the only candidates for consideration. Existential autonomy, the right to determine for ourselves some of the existential conditions under which we wish to develop our ways of life and relations to information technology, could be another. ${ }^{6}$ Another, less obvious candidate for consideration is the value of beauty. As wireless computational technology becomes embedded in more and more objects and so turns these objects into data-processing devices, the task of getting these devices to do what they can do becomes a matter of greater and greater complexity for the user. Such complexity cannot simply be managed by understanding how to interact effectively with smart machines. There is also the matter of being able to address problems that arise when these devices break down. Not only can we expect that as we become more and more dependent on such devices in the context of our everyday activities there will be more that will go wrong in the course of our use, we can also anticipate that systemic breakdowns will occur with other devices to which these ones are networked. A case can be made that, as this happens, more and more of our time will become occupied with trying to access and then implement the knowledge that would allow us to restore working order to smart machines and restabilize our immediate surroundings. Faced with the increasing necessity of spending time in activities whose focus is on the myriad of minutiae involved with repairing, restoring, and restabilizing, one might very well wonder if our capacity to recognize beauty and appreciate the esthetic character of our surroundings - a capacity that

${ }^{6} \mathrm{I}$ defend the value of existential autonomy in "Philosophy, Privacy, and Pervasive Computing (Michelfelder 2010)." 
demands we be immediately receptive to singularity, integrity, and wholenesswould suffer as a result. ${ }^{7}$

Let me wrap up this point regarding the importance of focusing ELSI-ICT research on those values that are foundational and intrinsic by turning once more to Sagoff (2008). In situations where the value of "sustainability" is brought forward as a crucial value to uphold, we would, he indicates, be well advised to step back and ask ourselves: "What is it that is to be sustained?"(p. 174). Whether one takes them to be intrinsic or not, the values that can be disclosed by addressing that more basic question are those that make the value of sustainability matter for us and vital to preserve. By analogy, when the more instrumental values of personal privacy or data security or human safety are brought forward as crucial values to uphold, as they tend to be when ELSI-ICT research is focused at the level of the particular artifact, it is worth taking a step back in order to ask about those other human goods to which these values point. Admittedly, in the context of ICT, discussion of the impacts of these larger goods tends to be more speculative than reflection on values that are more immediate and instrumental. But without attending to the former, we run the risk of losing sight of the larger picture and of missing critically important goods which not only need to be considered in their own right but also can serve as a horizon against which to gauge the threats or benefits posed by ICT-R\&D with respect to these more instrumental values as well.

\section{Giving New Frames to Ethical Questions}

Another, and related, advantage to such a holistic, future-oriented approach to ELSIICT is that it opens up the possibility for ethical questions associated with emerging ICTs to be meaningfully reframed in light of considerations that come to the fore only upon the adoption of a wider perspective. These considerations are ones that might otherwise remain inconspicuous if reflection on ICT-ELSI is focused on particular technologies whose development is near to or has already reached the stage of product implementation.

For a specific illustration of this advantage, let us turn to the question of privacy. By and large, when it comes to looking at concrete information technologies, the question of privacy is framed as an issue of how to best safeguard the privacy of individuals from unwanted intrusions into their online environments and how to best protect the privacy of personal data from unwanted collection, disclosure, and use. ${ }^{8}$ A case in point of such a frame can be found in a recent, excellent analysis of the ethical and social impacts of face-recognition technology (FRT) prepared by Lucas

\footnotetext{
${ }^{7}$ Looked at from such a perspective, the values associated with our material environment are similar to those associated with the natural environment, particularly as expressed by Aldo Leopold in his famous dictum that "a thing is right when it tends to preserve the integrity, beauty, and stability of the biotic community" (Leopold 1949).

${ }^{8}$ Lest the distinction I am drawing here between an unwanted intrusion into an online environment and the online collection of personal data seem unclear, by the former I have in mind such things as pop-up messages that appear on some shopping websites once a user has spent some time browsing the site, in which a representative of the site asks if the user needs assistance and volunteers to engage the user in an online conversation.
} 
Introna and Helen Nissenbaum (2010). Following an in-depth look at both actual and "test-case" uses of this technology, and an exploration of reasons as to why this technology might not work as well as anticipated once it is removed from testing conditions and placed in actual use, the authors propose a "default" mode for how it might be ethically used in security-related settings: namely, that all face-to-storedimage matches be taken as "potential false positives" until verified by a different source of information (p. 44). Coupled to this proposal is an array of additional suggestions as to what could be done to protect personal privacy in settings where this technology is implemented, such as taking steps to ensure that individuals have "opted-in" to the use of their facial images in image databases and to develop and publicize policies on information access and use.

I take it that Introna's and Nissenbaum's approach resonates well with Nordmann's and Rip's recommendation for how ELSI researchers can make responsible contributions to public discussion of emerging technologies. Their suggestions mentioned above emanate from, and are tightly associated with, the current technical capacities of face-recognition software, which is not yet sophisticated enough to be able to pick out a particular person from a crowd. Introna and Nissenbaum are careful to limit their speculations about where this technology might be headed in the future, venturing to imagine only that as yet undeveloped multimodal recognition technologies, ones that would for example combine face recognition with voice recognition, could improve the success rates of recognizing particular individuals in the context of a large group. "There are good reasons," they write, "to believe that it will still be some time before FRT will be able to recognize 'a face in the crowd' (in uncontrolled environments) with any degree of accuracy and consistency" (p. 47).

Suppose, however, that we were to take the question of the ethical impacts of face recognition software and consider it within a broader, albeit more speculative, frame. In turning now to look at this question, I do so in agreement with at least one aspect of Nordmann's and Rip's critique of speculative ethical thinking, namely that if such thinking is focused on the potential impacts of a single, far-fetched technological application, such consideration would be unproductive. The opposite could be true, however, if the "what if?" of speculative ethical thinking were to open up onto another question. That question is how such an application might interact with others in shaping the material conditions and social contours of the environments within which we live.

With respect to the particular example of FRT just mentioned, wondering about such a question could take the form of looking at the growth of the interest in the use of this technology in contexts beyond those of protecting national security or monitoring for those with a criminal background in airport terminals, football stadiums, and other settings. Currently, software aimed at recognizing general features of people in public spaces is under development. NEC's FieldAnalyst, for example, is reported as having the ability to discern the gender as well as the approximate age of a particular individual. ${ }^{9}$ Arguably, the use of such technology for the purposes of targeted marketing to a specific person within a shopping mall or the like would not constitute an invasion of privacy in the classical sense, as the

\footnotetext{
$\overline{{ }^{9} \text { A description of FieldAnalyst }}$ can be found at http://www.popsci.com/category/tags/face-recognitionsoftware and http://www.tokyomango.com/tokyo_mango/2007/10/new-nec-camera-.html.
} 
information gained about that person is the same that a normal adult passerby could also discover. Such use would, though, contribute to a developmental trend within ICT of "personalizing" public space. This trend, in turn, can be seen as part of an even wider trend within converging technologies to "personalize" our experiences according to our interests and needs - a trend to which numerous technologies, from those still on the drawing board such as personalized medicine to others already integrated with our everyday use of information technologies — think MyYahoo! — attest.

This quick sketch shows that what was initially framed as a problem of privacy can, upon stepping back and looking at a wider and more future-oriented picture, become re-framed as a problem of the increasing personalization of individual experience through the use of ICTs. Just as there are a number of human goods which depend on privacy for their realization, we could identify other human goods, among them our capacity to be curious and our ability to identify and empathize with the needs and interests of others, whose realization and so their ability to contribute to a life of human flourishing could be threatened by such increasing personalization. This other and broader frame is arguably not only worth considering with respect to the development of ICTs in the very early stages of development but also worth taking into account with regard to ICTs whose development is already well underway, as it could still help to influence their development as well as provide additional reasons in support of robust policies concerning their implementation and use.

\section{Voicing Difficult Questions}

From the example discussed above, it is but a short stretch to recognize a third risk philosophers run by not thinking speculatively in the context of ICT-ELSI. This is the risk of not asking hard, pointed, and critical questions, chief among them the question of whether a particular speculative technology ought to be developed at all. Raising these questions, I believe, is part of what it is for ethicists or philosophers of technology, as Sagoff (2008) emphasizes, to do their own work and not that of others; in his words, for each "cobbler to stick to his or her last" (p. 15). If the role of the ethicists and philosophers of technology in ICT-ELSI research is limited to looking at the possible consequences of technologies into which a significant amount of R\&D dollars have already been poured, their role would be primarily one of managing and mitigating whatever negative ethical and social consequences of these technologies might emerge. An expanded role would allow for the freedom to raise the question of whether investments should be put toward the development of particular technologies at all. The broader values and frames for discussion such as those described above can provide "traction" for deciding if and when such a question ought to be raised.

Here, again, an insight drawn from environmental philosophy may be helpful. Bryan G. Norton, in "Sustainability, Human Welfare, and Ecosystem Health," notes that we should refrain from taking a particular course of action if it could result in "irreversible catastrophe": not only species extinction but also irreversible biological, cultural, and political impoverishment (Norton 2003). Let us imagine that ICT-ELSI 
analysis of the larger picture connected to a particular technology still in the earliest stages of development reveals that such impoverishment could be a possible outcome of its release and adoption. In other words, suppose it yields the result that to develop this technology might lead to the eradication of the "critical habitat" sustaining one or another value recognized across a broad demographic of the world's population as being deeply and fundamentally important. It is reasonable then to hope that such analysis could serve at least to put a firm check on, if not entirely bring to a halt, the possibility of investing in its development, rather than being summarily dismissed as "merely" speculative thinking.

In short, despite the concerns of Nordmann and Rip, there is an important role for ethical thinking of a speculative nature to play in looking at the ELSI of emerging technologies in general and of ICT in particular. There is benefit to be gained from taking a focus that considers but looks past the immediate present to the future, even a future that might not turn out to be realizable for technical reasons or because of the nature of our own biological and neurological make-up. That benefit is in giving an invitation to all stakeholders involved to give consideration both to the ethical challenges presented by specific ICT technologies and to the question of how these technologies might work in consonance with ones projected but not yet developed to shape the contours of our material environment and the quality of our lives. One need not dismiss the contribution of speculative ethical thinking to ICT development and policy-making because of its orientation toward a distant and uncertain future. Of course, just as some of the promises associated with emerging ICTs will turn out to be more closely associated with science fiction than science, some speculative ethical reflection on how these technologies will impact society will turn out to be far-fetched, even silly. But when we think toward the future, we keep the world as a whole within our sights, and by so doing keep attuned to values, frames for discussion, and broad-reaching questions that can serve to guide ICT-R\&D and policy-making.

Again, this is not to say that philosophers ought to stay away from the trenches and from the difficult work of projecting and analyzing the social and ethical impacts of specific and almost marketable "smart" devices. It is however to say that the responsibilities of philosophers of technology rest not only in thinking about emerging technologies in the plural but also in thinking about technology in the singular as well.

\section{Prioritizing Within Speculative Ethical Thinking}

Suppose one accepts that there are benefits to speculative ICT-ELSI thinking, and also recognizes that at least some claims made about possible technologies, claims about transhumanism, for example, are simply too far-fetched for even the speculative ethicist to seriously consider. How then to sort out the speculative claims worth thinking about from those that are not? Would speculative ethicists be wasting their time in reflecting on the possible effects of "uploading" human minds into computers or into robots, or "uplifting" animal minds so they can have enhanced, human-like cognitive capacity? Where would it be reasonable to draw the line? Should for example the speculative ethicist not waste time with those claims 
that are wildly speculative in nature, in order to direct his or her attention to others that are "tamer" and associated with technologies more likely to see the light of day?

As Rebecca Roache points out in a thoughtfully considered defense of speculative ethical thinking, it is not necessarily a waste of time for speculative ethicists to worry about the potential impacts of wildly speculative technologies (Roache 2008). The "explosion in computer processing power" is just one example that she gives of how ideas once thought to be far-fetched have been developed and turned into products that are now a part of our everyday technological environment (p. 322). We humans, she rightfully notes, are not very skilled when it comes to identifying which technological ideas are realizable and which ones are not (p. 323). I agree with Roache that while we might want to exercise caution about the amount of time we devote in reflecting on highly futuristic scenarios - such as the development of mind-machine interfaces, which Nordmann and Rip specifically cite - the very fact that a scenario is highly futuristic ought not to lead us immediately to conclude that thinking about the ethical impacts of the speculative technologies it involves is a waste of time. But if we cannot draw the line here, where should it be drawn?

Another approach for evaluating what speculative technologies are worth attending to in terms of their social and ethical impacts, and which ones are not, would be to use a weighted cost-benefit analysis. This is the approach Roache favors. Using such an analysis, we could decide to think about the impacts of particular speculative technologies which, although at present we would judge their likelihood of being brought to fruition as quite low, promise benefits that are extraordinarily positive in nature. By the same token, if such technologies were to be developed and would carry a very high potential of creating extraordinarily negative harms, such as the harm mentioned in the previous section of creating an irreversible loss of a value we hold quite highly, it would be reasonable for us to contemplate these technologies as well.

Taking this approach, we might decide that it would be worthwhile to speculate about the potential impacts of mind-machine interfaces, despite the fact that the idea of such interfaces is arguably far-fetched and despite the many unknowns associated with designing and implementing them. One of the chief promises of these interfaces is that their development could give those who are severely restricted in their mobility the gift of the ability to move their limbs or a cursor on a computer screen. If we believe that such benefits would be extraordinary in nature, then speculative consideration of the ethical and social impacts of these interfaces would be time well spent.

Contrary then to Nordmann and Rip, I agree that mind-machine interfaces are an appropriate object of ICT-ELSI speculation, but I do not believe this as a result of taking the cost-benefit approach just described. Such an approach, as well as the overall thrust of Nordmann's and Rip's emphasis on the need to concentrate thinking on the possible impacts of technologies already advanced in their development, is arguably rooted in a modernist understanding of technology in which tools, machines, and consumable objects are taken as the basic components and as the starting points for an understanding of their ethical impacts. Here too, we can borrow a page from environmental ethics, in particular from the emerging field of climate change ethics, in order to see the problematic nature of this approach. One of the difficulties with which this field struggles is the question of how to predict the 
impacts of particular actions affecting the climate. Hardly noticeable impacts of individual actions add up over time to create severe, aggregate impacts, which in turn could be more severe in some places than in others. These individual impacts can also interact with one another to create synergistic effects. It is the recognition of these particular kinds of interrelational effects brought about by global climate change that leads the American environmental philosopher Dale Jamieson to argue that:

We cannot reliably aggregate the effects by evaluating each impact and combining them by simple addition. But since the interactions are so complex, we have no idea what the proper mathematical function would be for aggregating them (if the idea of aggregation even makes sense in this context.) It is difficult enough to assess the economic benefits and costs of small scale, local activities. It is almost unimaginable to suppose that we could aggregate the diverse impacts of global climate change in such a way as to dictate policy responses (Jamieson 2003, p. 375).

If one were to replace the phrase "global climate change" with "emerging technologies," what Jamieson writes would still hold true. It is in very large part the novel and unpredictable ways that these technologies will interact with one another-for example, nanotechnologies and biotechnologies combining with information and computer technologies - that is cause for ethical attention, but it is precisely because these technologies will interact with one another in novel and unpredictable ways that the cost-benefit approach suggested by Roache as a way of directing speculative ethical attention where it is most needed runs into difficulty.

If neither of the two options discussed so far are promising ways of answering the question of how to prioritize within speculative ethical thinking, what other options might be more fruitful? Here, I would like to offer two suggestions. One is that it is reasonable to focus ELSI attention on those futuristic technologies that might, and given what I have just been saying it is important to underscore that "might," have an extremely detrimental or extremely positive impact on our "keystone" values. In using the word "keystone" here, I am of course borrowing a term from environmental ethics, where it is most often used to designate particular kinds of species or also resources. In the words of Brian Norton:

Some resources, such as timber or salmon runs, are seen as 'keystone' resources in economic and community development. These resources become keystones in the local economy in that maintenance of jobs in the region, in extraction, in transportation, in tourism, and in manufacturing, all depend on protecting these resources (Norton 1999, p. 147).

What among the values that we hold close might fall into the category of keystone values? We might simply wish to say that those values on which our ability to thoughtfully address the kinds of issues we are looking at here-values such as autonomy and trust-would fall under this heading. If a particular futuristic technology might deeply enhance or extremely threaten the sustainability of these keystone values, we ought not to dismiss such technology from our ethical reflection, no matter how far-fetched or speculative. 
My second suggestion is that we need to pay particular attention to those technologies, neuromarketing and scanning for our "intentions" among them, that raise the prospects of bypassing our sense organs to directly influence our neural make-up and so bring about a transformative change in the phenomenological character of our lived experience. The connection of this suggestion to the one just given should be clear, as our ability to act autonomously and with trust would be radically compromised were such technologies to be developed and introduced. On the other hand, the ELSI of those technologies that promise to extend the range of our senses, keeping the phenomenological character of our lived experience intact, would also be worth speculative consideration.

With these two options as a guide, we could again conclude that it would be valuable to speculate about the ethical impacts of mind-machine interfaces, as they might be able to make a vital and enormous contribution toward extending not only autonomy but also the scope and reach of the senses for those who are disabled.

In short, just as Jamieson points out with respect to global climate change that "what we need are new values that reflect the interconnectedness of life on a dense, high-technology planet" (Jamieson 2003, p. 377), we also need to be mindful of the interconnectedness of emerging technologies when engaged in reflecting on their possible ethical impacts. For that reason, I believe thinking speculatively about such impacts is not wasted or irresponsible thought, but its opposite instead.

Acknowledgments Versions of this paper were presented at Lafayette College in Pennsylvania (USA) in February 2010 and at the 1st ETICA Conference at the University of Rovirà y Virgili (Tarragona, Spain) in April 2010. My thanks go to Dr. Sharon Jones, the Director of the Engineering Program at Lafayette College, for graciously inviting me to speak on that campus, and to Dr. Bernd Stahl, the Director of the ETICA project. I am especially grateful to the two anonymous reviewers of my paper for the ETICA conference for their insightful and helpful comments, as well for the comments of participants in the ETICA conference, especially Rafael Capurro.

Open Access This article is distributed under the terms of the Creative Commons Attribution Noncommercial License which permits any noncommercial use, distribution, and reproduction in any medium, provided the original author(s) and source are credited.

\section{References}

Grunwald, A. (2010). From speculative nanoethics to explorative philosophy of nanotechnology. Nanoethics, 4, 91-101.

Harper, R., Rodden, T., Rogers, Y., \& Sellen, A. (2008). Being human: Human-computer interaction in the year 2020. Cambridge: Microsoft Research Ltd.

Introna, L., \& Nissenbaum, M. (2010). Facial recognition technology: A survey of policy and implementation issues. Lancaster University Management School Working Paper.

Jamieson, D. (2003). Ethics, public policy, and global warming. In A. Light \& H. Rolston III (Eds.), Environmental ethics (pp. 371-379). Oxford: Blackwell Publishing.

Leopold, A. (1949). The land ethic. In A sand county almanac. New York: Oxford University Press.

Michelfelder, D. (2010). Philosophy, Privacy, and Pervasive Computing. AI \& Society, 25(1), 61-70.

Mnyusiwalla, A., Daar, A., \& Singer, P. (2003). Mind the gap: Ethics and science in nanotechnology. Nanotechnology, 14, R9-R13.

Nordmann, A. (2007). Technology naturalized: A challenge to design for the human scale. In P. Vermaas et al. (Eds.), Philosophy and design: From engineering to architecture (pp. 173-184). Dordrecht: Springer. 
Nordmann, A., \& Rip, A. (2009). Mind the gap revisited. Nature Nanotechnology, 4(5), 273-274.

Norton, B. (1999). Ecology and opportunity: Intergenerational equity and sustainable options. In A. Dobson (Ed.), Fairness and futurity: Essays on environmental sustainability and social justice (pp. 118-150). Oxford: Oxford University Press.

Norton, B. (2003). Sustainability, human welfare, and ecosystem health. In Searching for sustainability: Interdisciplinary essays in the philosophy of conservation biology. Cambridge: Cambridge University Press.

Roache, R. (2008). Ethics, speculation, and values. Nanoethics, 2, 317-327.

Roco, M., \& Bambridge, W. (2002). Converging technologies for improving human performance. Arlington: US National Science Foundation and Department of Commerce.

Sagoff, M. (2008). The economy of the earth. Cambridge: Cambridge University Press. 